\title{
Acontecimento e ato: reflexões da psicanálise sobre as repercussões de Maio de 1968
}

\author{
Miriam Debieux Rosaa* (iD \\ Isaías Gonçalves Ferreirab (iD) \\ aUniversiade de São Paulo, Instituto de Psicologia. São Paulo, SP, Brasil \\ bPontifícia Universidade Católica de São Paulo, Departamento de Psicologia Social. São Paulo, SP, Brasil
}

\begin{abstract}
Resumo: $O$ artigo surge da inquietação de psicanalistas diante do sucesso ou fracasso dos movimentos sociais como resposta à atual crise institucional, política e social. Destacamos o dilema epistemológico e político presente na indagação que percorreu o movimento de Maio de 1968: as estruturas descem ou não para a rua? O caminho adotado é examinar os efeitos do movimento e cotejá-los com as concepções teóricas de Lacan. O saldo que obtemos desse balanço crítico foi considerar Maio de 1968 como um acontecimento que nos lembra de que é possível estruturar uma nova forma de política. Nomear a vergonha dos excessos nos laços sociais de nosso tempo pode conferir dignidade ao significante e produzir um ponto de basta pela dimensão da ética e da singularidade. Tal posição produz giro discursivo, incitado pela coragem de ter uma idéia e a possibilidade de reinvenção do laço social por sucessivas subversões e revoluções.
\end{abstract}

Palavras-chave: acontecimento, laço social, vergonha, política, psicanálise.

Estamos em um momento em que parece estarmos retrocedendo em campos que julgávamos já assentados e garantidos, não apenas quanto à gestão política e democrática, mas também em relação aos processos jurídicos, aos direitos humanos e à constituição de dispositivos que garantam o reconhecimento de diferenças. Constatamos o que pode ser considerado o eixo central que configura a composição de determinadas teses do filósofo italiano Giorgio Agamben (1995/2007, 2007/2011) sobre política contemporânea e suas implicações jurídico-institucionais.

Temos presenciado, nos últimos anos, na política brasileira, a gestão social na lógica da guerra (Rosa, Penha, \& Alencar, 2017) caracterizada por uma verdadeira suspensão de debates políticos, substituídos por palavras de ordem excludentes e radicais, difusoras do ódio, numa tentativa truculenta de silenciar o oponente, seja por uma carga de preconceitos e humilhações (violência simbólica), seja pela promessa do uso de armas e assassinatos de políticos e líderes de movimentos sociais, como também pela explicitação da intensão de extermínio de populações marginalizadas, sem investigação e punição (violência física).

Nessa esteira, é urgente analisar os processos políticos de transformação social e as estratégias e impasses na luta pelos direitos com o objetivo de posicionar a potência dos movimentos sociais. Com efeito, muitas são as questões sobre a função, o sucesso ou fracasso dos movimentos sociais como

*Endereço para correspondência: ferreira.is@hotmail.com resposta aos diferentes modos de segregação, bem como sobre a interpretação que a articulação entre psicanálise e política nos permite lançar na análise dos fenômenos sociais. Nesse sentido, Maio de 1968 foi um acontecimento que, apesar das ambivalências, ainda ecoa em nossos dias como uma espécie de marco histórico que não cessa de nos lembrar de que é possível estruturar uma nova forma de política, não de um partido, mas, antes, partidária do lugar comum que reconheça a expressividade das diferenças.

Diante de tais delineamentos, pretendemos situar as reflexões da psicanálise lacaniana sobre as repercussões de Maio de 1968, considerando seus efeitos e implicações para a contemporaneidade, principalmente no que concerne à teoria dos laços sociais proposta por Lacan na década de 1970.

\section{A ambivalência das análises sobre Maio de 1968}

A efervescência produzida por Maio de 1968 encaminhou uma ambivalência das análises realizadas, que indicam ora avanços e ora retrocessos, inclusive por seus participantes e protagonistas. Essa ambivalência de diagnóstico nos mostra como Maio de 1968 foi um acontecimento complexo. Geralmente, o problema de sua interpretação consiste no fato de isolar apenas um aspecto em detrimento de outros. Badiou (2009/2012) defende que "a particularidade do Maio de 1968 francês foi ter entrelaçado, combinado, sobreposto quatro processos que afinal eram bastante heterogêneos" (p. 30). 
De acordo com Badiou (2009/2012), de um ponto de vista geral e abrangente, o Maio de 1968 francês pode ser entendido por, pelo menos, quatro ângulos:

1. A revolta da juventude universitária e secundarista: um fenômeno mundial, com impactos no México, na Alemanha, na China, na Itália, nos EUA etc.

2. A maior greve geral da história francesa, na qual um grupo de jovens operários iniciou o movimento de forma externa às instituições operárias oficiais, ou seja, as coisas aconteceram fora das organizações sindicais. Vale lembrar que, em 1967, ocorreram greves intensas, portanto, antecipando o Maio de 1968 operário e estudantil.

3. O Maio libertário, que representou uma espécie de componente ideológico, posicionando diversos efeitos no laço social, dentre os quais: determinadas mudanças nos costumes, novas relações amorosas, $o$ engendramento de liberdades individuais, o movimento das mulheres (feministas), os direitos e a emancipação dos homossexuais, assim como novas expressões culturais que se inauguravam, isto é, "um novo teatro, uma nova forma de discurso público, um novo estilo de ação coletiva"1 (Badiou, 2009/2012, p. 32).

4. O Maio de 1968 que, de certa forma, ainda perdura no tempo e determina o futuro. Em primeiro lugar, houve um questionamento profundo de uma velha concepção de política (entre 1968-1978). Em segundo lugar, um esgotamento nesse questionamento, que foi seguido pela tentativa de estabelecimento gradual de uma nova concepção de política (entre 1970-1980). Esse aspecto do Maio de 1968 foi amplamente animado pela curiosa pergunta: "O que é política?". Aqui se desenha toda a crítica que Badiou (1994) empreende sobre a política partidária e sua relação cínica com o Estado capital-parlamentarista.

Podemos ainda acrescentar, talvez, um quinto Maio de 1968, relacionado a uma espécie de esgotamento da perspectiva estruturalista encabeçada por Lévi-Strauss. O aporte estruturalista lévi-straussiano

1 Esses três componentes foram representados por determinados lugares simbólicos: (1) a Sorbonne ocupada para os estudantes universitários; (2) as grandes fábricas de automóveis para os operários; (3) a ocupação do teatro Odéon para o movimento Maio libertário (Badiou, 2009/2012). norteava quase todo o campo de releitura epistemológica da linguística, da antropologia e da psicanálise, caminhando na direção de uma superação do paradigma evolucionista das ciências sociais que autorizava um enfoque colonialista das sociedades. No entanto a crítica ao estruturalismo consistiu em reconhecer que o lugar da história estava eclipsado e que o sujeito enquanto categoria estava morto e, com isso, recolocava-se em pauta a questão da transformação social em sua maior abrangência (Motta, 2012).

Dessa forma elaborou-se um movimento intricado de revisão crítica ao estruturalismo clássico inaugurado por Lévi-Strauss, tendo a visada estruturalista representado um verdadeiro programa de investigação que retomou e generalizou o método das oposições empregado por Saussure para estudar a linguagem: fala-língua, significado-significante, diacronia-sincronia etc. Esse é o arcabouço teórico que Saussure postula para analisar a economia dos fatos simbólicos, tendo em vista que as trocas sociais têm uma estrutura de linguagem. É a partir desse contexto epistemológico que Lévi-Strauss (1974/2008) elabora sua antropologia estrutural.

Antonio Mota (2012), em seu artigo "As estruturas não descem às ruas: Lévi-Strauss, mai soixante-huit e o fim do estruturalismo", localiza que o formalismo estrutural de Lévi-Strauss produziu um modo fixado de interpretação dos fenômenos sociais, isto é, guiou-se por uma matriz mítica de interpretação. Esse procedimento, contudo, obstruiu uma consideração mais abrangente e dinâmica das transformações sociais em seu eixo histórico. Isso produziu uma forma de esvaziamento do lugar ocupado na história pelos movimentos sociais, bem como do pertencimento e da reestruturação da vida social (em sua forma emancipatória) que determinados indivíduos buscavam por intermédio de um engajamento político.

Nessa mesma linha argumentativa constituiu-se um dos mais importantes pontos de inflexão crítica na chamada geração pós-estruturalista, composta por Michel Foucault, Gilles Deleuze e Jacques Derrida, entre outros. $\mathrm{O}$ movimento pós-estruturalista procurou superar determinadas concepções do estruturalismo clássico que estavam de certo modo superadas, tais como o idealismo, o racionalismo, o formalismo ${ }^{2}$ e a universalidade das estruturas e dos modelos mitológicos. Como resultado, a interpretação das sociedades não mais poderia ser reduzida a uma metanálise estrutural em seu eixo totemista.

Ainda seguindo a análise de Motta (2012), percebe-se como o movimento considerado pós-estruturalista recebeu todo seu vigor em autores

\footnotetext{
2 Há, portanto, um questionamento pós-estruturalista decisivo que consiste, especificamente, no kantismo que Lévi-Strauss importa para o método estrutural, em sua expressão idealista, racionalista e formal.
} 
como Foucault e Derrida ${ }^{3}$. Por exemplo, Foucault estava preocupado com a ordem discursiva e suas regras simbólicas de formação no âmbito histórico-social, na medida em que reproduziam relações de poder e um império de saber. Derrida, por sua vez, considerou que o estruturalismo lévi-straussiano estava fincado em uma metafísica da presença, como uma forma privilegiada de responder à influência exercida pelo idealismo saussuriano do signo linguístico. Esse modus operandi produziu uma forma estrutural (centrada e estática) que obstruiu a força interna de seu movimento.

Para Mota (2012), Derrida encontra no termo "força de viver" o móbile que tornou possível o acontecimento de Maio de 1968. Isso desencadeou consequências importantes para a reorganização das relações sociais, pois produziu uma crise na estrutura pensada enquanto um metamodelo. Assim, seu lugar privilegiado foi questionado.

Veremos que a posição de Lacan (1968-1969/ 2008) sobre a relação entre sujeito e estrutura encontrou um encaminhamento diferente, pois colocou o real em questão, isto é, abordou o estruturalismo em sua condição de seriedade, tendo em vista que a estrutura é o real. E o próprio sujeito (\$) é o efeito do gozo (a) da repetição significante (S1-S2), sendo, portanto, uma resposta do real.

\section{Lacan e a subversão da psicanálise}

O trajeto que Lacan realizava de seu apartamento até o Hospital Sainte-Anne lhe reservava tanto a paisagem parisiense dos anos de 1920, contemplada pelas janelas do metrô, quanto outra viagem, essa nas páginas da monumental obra de Karl Marx, O capital. Sabemos isso porque o próprio Lacan (1968-1969/2008) confidenciou que foi nessas condições que leu, por volta dos seus vinte anos, a principal obra do marxismo. É certo que sua interlocução com Marx só ocorreu no final da década de 1960, mas as sementes da filosofia de um Marx maduro permearam o terreno intelectual do jovem Lacan.

3 O problema da estrutura em Deleuze (1969/1998) recebe um questionamento diferente, pois se refere a uma lógica do sentido que coloca em questão um jogo entre o sentido e o não-senso. Com isso, é possível localizar uma crítica à primazia saussuriana no entendimento da linguagem, por intermédio da importância que Deleuze confere ao não-sentido (não-senso), sendo, portanto, sustentada em sua amplitude conceitual no modelo estoico de interpretação dos signos. Assim, forma-se um caráter híbrido entre a obra de Lewis Carroll e a filosofia dos estoicos sobre as manifestações do paradoxo. E isso pela via do acontecimento e do devir dos fluxos constantes, já que o paradoxo questiona o sentido único enquanto designação das identidades fixas. Nessa perspectiva, Deleuze recorre a uma definição dos corpos enquanto acontecimentos que remetem aos efeitos incorporais. O sentido, assim, é uma fronteira e um espelho que refletem um jogo de proposições (sentido e não-sentido) em uma concatenação de efeitos incorporais causados pela relação dos corpos. Dessa forma, o acontecimento-devir dos corpos desponta como uma forma de subverter a herança do dualismo platônico em sua tentativa de duplicação e depreciação da experiência corporal.
Se, por um lado, Marx desvela o Real do antagonismo social da luta de classes, assim questionando o edifício utópico da sociedade burguesa do século XIX, por outro, Lacan identifica que Freud, com a descoberta do inconsciente, questiona o ideal de autonomia da razão erigida pelo iluminismo e solidificada pelo positivismo. Com sua visada, localiza que o expediente freudiano posicionou uma espécie de ruptura, de corte epistemológico com o saber médico-psiquiátrico do século XIX, pois construiu o dispositivo da escuta analítica e reposicionou tanto a racionalidade diagnóstica sobre as afecções mentais como os operadores clínicos do tratamento das neuroses, promovendo a redistribuição de uma nova psicopatologia - a nosografia e a nosologia, propriamente psicanalíticas.

Com efeito, Lacan recupera o aspecto subversivo da obra de Freud, justamente o que foi recalcado pelos pós-freudianos, que de forma sintomática privilegiaram determinados aspectos da teoria freudiana em detrimento de outros. Esse movimento subversivo parece ter também se perdido nas leituras lacanianas que se seguiram.

Diante desse contexto, a proposta psicanalítica, freudianamente inspirada, é retomada por Lacan nos anos 1950, a partir da qual estabelece um programa crítico de investigação sobre a direção dada aos seus conceitos, a sua teoria e a sua prática, o que também incluiu a dimensão política temperada por uma crítica social renovada.

Desse modo, Lacan endereça uma crítica declarada contra a Associação Internacional de Psicanálise (International Psychoanalytical Association - IPA), que apresentava uma ortodoxia e um engessamento na prática psicanalítica. Sua bula colocava restrições específicas com relação à duração das sessões e sua frequência, instituindo assim um contrato rígido para a direção do tratamento (Quinet, 1991/2009).

Em $1953^{4}$, data oficial do início dos seminários de Lacan, ocorre a primeira cisão no campo psicanalítico francês, em torno da configuração da análise, no que concerne tanto às sessões (duração e frequência) quanto à exigência de que os analistas tivessem formação médica esta última proposta por Sacha Nacht.

Tendo esse horizonte descortinado, Lacan (1953/1998), em sua releitura de Freud, procurou articular desde seus primeiros textos a dimensão política, afirmando que o inconsciente, enquanto a Outra Cena (Der Andere Schauplatz), é a história do sujeito; afirma também que "deve renunciar à prática da psicanálise todo analista que não conseguir alcançar em seu horizonte a subjetividade de sua época" (p. 322).

De acordo com Shepherdson (2007), a segunda divisão ocorreu dez anos depois, no outono de 1963, quando o grupo que se formou durante a primeira cisão

4 A cisão de 1953 com a Sociedade Psicanalítica de Paris possibilitou a criação da Sociedade Francesa de Psicanálise (SFP). 
excluiu Lacan ${ }^{5}$ de sua lista de analistas em treinamento autorizados, a fim de obter o reconhecimento oficial da Associação Psicanalítica Internacional. Essa situação obrigou Lacan a cancelar seu seminário no Hospital Sainte-Anne, onde ministrava cursos há dez anos. Todavia, em 1964, é acolhido na Escola Normal Superior (École Normale Supérieure) por Louis Althusser, Fernand Braudel e Claude Lévi-Strauss. Assim, começou a ensinar pela primeira vez para uma audiência universitária, portanto, fora do meio estritamente psicanalítico. É certo que "filósofos como Jean Wahl e Jean Hyppolite tinham se interessado por seu trabalho há muitos anos" (Shepherdson, 2007, p. 96), contudo, com essa mudança de ambiente, não havia mais a incômoda exigência de apresentar credenciais especiais para participar de seu seminário. "O seminário era agora aberto ao público, consideravelmente maior do que já havia sido até então, e seus participantes eram principalmente da universidade" (Shepherdson, 2007, pp. 96-97). O seminário que Lacan havia planejado, "Os nomes do pai" (Les noms-du-père), fora interrompido após a realização de apenas uma sessão. Portanto, quando se mudou de Sainte-Anne para a École Normale Supérieure, propôs um programa de investigação diferente, que foi publicado como "Os quatro conceitos fundamentais da psicanálise" (Lacan, 1964/2008). Sua proposta, então, consistiu em escavar no campo psicanalítico "os fundamentos da psicanálise", ou seja, seus princípios fundamentais.

É de então o famoso texto Freud e Lacan: Marx e Freud, de Louis Althusser (1964/1985), que pode ser considerado, "antes de mais nada, um texto de luta teórica, um ato político" (Evangelista, 1964/1985, p. 11). Como evidenciamos em artigo anterior (Rosa, 2004), nesse texto, Althusser postula que cabe à psicanálise elucidar alguns problemas na articulação entre sujeito e sociedade, isto é: pensar a relação da estrutura formal da linguagem com as estruturas concretas de parentesco, considerando as formações ideológicas em que são vividas as funções específicas da paternidade, da maternidade e da infância; questionar como a variação histórica dessas estruturas pode afetar a subjetividade; indagar quais são as relações da psicanálise com sua condição de aparecimento histórico e quais são suas condições sociais de aplicação. Tendo esse contexto em vista, Althusser (1964/1985) propõe que a psicanálise construíra sua própria metodologia de pesquisa, isto é, constituiu um campo de conhecimento que articula uma prática, uma técnica e uma teoria, que define tanto um objeto de estudo (o inconsciente), quanto um método de saber (o analítico). É, portanto, um conjunto

5 A Sociedade Francesa de Psicanálise excluiu Lacan de sua lista de analistas didatas, o que também significou sua rejeição da sociedade fundada pelo próprio Freud (IPA). Por essa razão, Lacan (1964/2008), na primeira lição do Seminário livro 11, nomeia sua exclusão como uma excomunhão, similar à que o filosofo Baruch Spinoza sofreu pela Sinagoga Portuguesa de Amsterdã, por suas posições radicais sobre o estatuto de Deus (mecanismo imanente da natureza) e da Bíblia (obra metafórico-alegórica). (prático, técnico e teórico) de elementos que evidencia a estrutura de uma disciplina científica.

Nessa perspectiva, podemos concordar com o diagnóstico althusseriano sobre o empreendimento de Lacan, na medida em que a psicanálise lacaniana construiu um programa de investigação teórico-clínico envelopado por uma posição política claramente orientada para a queda dos ideais alienantes.

Dessa forma, a esfera ética da psicanálise se sustenta no campo do desejo e na dimensão do ato analítico, e não em normas preestabelecidas (contrato), tendo em vista que a direção de uma análise visa ao posicionamento do sujeito (analisante) diante da falta do Outro [S(A)] (Quinet, 1991/2009).

Nesse caminho, Lacan também empreendeu uma dura crítica à chamada Psicologia do Ego ( $l^{\prime} E g o$ psychology), que representava uma espécie de programa clínico da IPA, com o objetivo de desenvolver certo efeito clínico no qual o analisante (ego fraco) buscava continente no analista (ego forte), produzindo, assim, uma adaptação deste à realidade.

$\mathrm{O}$ conservadorismo chega a tal ponto que a leitura dos analistas da IPA com relação ao Maio de 1968 consistia em considerar que os "jovens estavam mal situados em relação ao seu Édipo, subentendendo que quem estivesse bem colocado em relação ao Édipo não se revoltaria" (Soler, 2010, p. 257).

Diante de tais delineamentos surge a seguinte indagação: o que se depreende quanto à transformação social pela posição de Lacan em relação ao acontecimento Maio de 1968?

\section{Do ato ao discurso, uma leitura possível sobre a suposta ambivalência de Lacan com Maio de 1968}

Durante a efervescência provocada por Maio de 1968, Lacan pronunciava seu Seminário, livro 15: O ato psicanalítico (Lacan, 1967). Neste, é possível observar um desenvolvimento específico sobre as dimensões do ato (ato falho, ato psicanalítico, passagem ao ato, acting-out) que nos permite pensar a estrutura do ato político enquanto um acontecimento. Dito de outro modo, o acontecimento é homólogo à dimensão do ato, na medida em que ambos apresentam coordenadas que não podem ser calculadas ou deduzidas a priori, sendo, portanto, seus efeitos apreendidos a posteriori.

Sob essa perspectiva, podemos isolar três momentos distintos nos seminários de Lacan sobre sua leitura do acontecimento Maio de 1968. O primeiro, quando Lacan interrompe a continuidade do seminário 15 por causa da greve convocada pelo Sindicato Nacional do Ensino Superior (SNESup). Na véspera da interrupção, Lacan participara de uma reunião com os líderes da Revolução Estudantil, mas não se pronunciara. No entanto, no dia 15 de maio, acontece outro encontro, no qual Lacan teceu os seguintes elogios ao líder estudantil Daniel Cohn-Bendit: 
venho me matando de dizer que os psicanalistas devem esperar alguma coisa da insurreição; há quem retruque: "o que esperaria de nós a insurreição?". A insurreição lhes responde: "o que esperamos de vocês, se for esse o caso, é que nos ajudem a atirar paralelepípedos". (Lacan, 1967, p. 277)

Em seguida, Lacan anuncia que os paralelepípedos e as bombas de gás lacrimogêneo preenchem a função do objeto $a$.

No trecho atribuído a Lacan, observamos que o que mobilizava a chamada insurreição era esse objeto fugidio (objeto $a$ ), que causa e direciona nosso desejo no mundo da vida. Participamos direta ou indiretamente dos movimentos "revolucionários", seja na rua, resistindo à violência com violência, seja no plano do discurso que instaura um campo de verdade que retorna na falha do saber. A greve é o sintoma social por excelência.

É certo que a filosofia do acontecimento insurrecional não pode andar de cabeça para baixo no idealismo do plano teorético. Todavia também não deve pensar com os pés. O plano da práxis deve se coadunar com o plano discursivo, constituindo e solidificando o campo político de ação, pela tática e pela estratégia. Nisso, os psicanalistas estão implicados e responsabilizados, e não apenas a universidade, pois o acontecimento produzido em Maio de 1968 não pode ser reduzido a meras turbulências. Antes, tratou-se de um fenômeno estrutural, em que as relações do desejo e do saber foram postas em questão. O campo do saber também é o campo de sua transmissão, que não se reduz ao desejo de saber no nível do Outro (Lacan, 1967).

Após a interrupção, Lacan retoma o seminário com um curso diferente, com uma temática que, como veremos, representou uma verdadeira interlocução com o pensamento marxista.

O segundo momento, portanto, aconteceu na segunda aula de seu Seminário, livro 16: De um Outro ao outro (Lacan, 1968-69/2008), no qual Lacan comenta os acontecimentos de Maio de 1968. Esse seminário traz reflexões importantes para responder à famosa frase que pintava os muros: "as estruturas não descem à rua" ${ }^{\prime \prime}$. Para responder a esses questionamentos, Lacan redefiniu a relação do real com a estrutura. Em um primeiro momento de seu ensino, Lacan (1960/1998) considerou que o campo do Outro se configura como um sistema de trocas simbólicas que regulam as relações sociais, tendo em vista que, em sua leitura estruturalista (lévi-straussiana) da obra de Freud, deduz o falo como o elemento que, estando fora do sistema simbólico, ao mesmo tempo estrutura e regula suas relações internas. No entanto essa coreografia coloca em evidência o jogo de possibilidades e impossibilidades escritas no próprio simbólico, o que levou Lacan (1962-1963/2005, 1964/2008)

6 Na velha lousa da Sorbonne também apareceu a famosa frase que serviu de standard para a crítica ao estruturalismo: "As estruturas não descem à rua" (Motta, 2012). a formalizar o objeto $a$ como uma forma de inscrever o real na própria estrutura simbólica. No chamado campo do gozo, a articulação se desenha a partir do real como impossivel, isto é, o não-simbolizável que posiciona a estrutura como o real (Lacan, 1968-1969/2008).

Nesse mesmo seminário, podemos localizar a data de batismo de sua articulação com Marx, no sentido forte do termo (Rosa, 2004). Assim, no final da década de 1960, Lacan (1968-1969/2008) anuncia a substituição de um modelo energético, propriamente freudiano, pela referência à economia política via concepção marxista - para Lacan, Marx foi o inventor do sintoma, ou pelo menos daquilo que podemos considerar como a dimensão de uma leitura sintomal da sociedade burguesa do século XIX. Com efeito, o psicanalista (Lacan) se aproxima do filósofo (Marx) pelo signo da curiosa homologia entre o mais-de-gozar e a maisvalia, que ocorre na ordem da estrutura enquanto real, na medida em que se funda na direção de um impossível. Portanto considerou ter encontrado um caminho mais propício para o desenvolvimento do campo do gozo.

Certamente, a inserção de Lacan nesse expediente consistiu em reconhecer que "o aparecimento da mais-valia no discurso tenha tido como condição a absolutização do mercado" (Lacan, 1968-1969/2008, p. 37). A mais-valia, portanto, é o produto nefasto da lógica capitalista, é aquilo que permite a mercadorização de tudo (Warenfetischismus), inclusive do próprio trabalhador, que se torna uma mercadoria. Dito de outro modo, a instituição de um mercado para o trabalho torna possível que um trabalho seja vendido no mercado.

Dessa forma, Lacan estabelece o modo pelo qual os seres falantes promovem o ordenamento do gozo, já que "o mais-de-gozar é uma função da renúncia ao gozo sob o efeito do discurso" (Lacan, 1968-1969/2008, p. 19). Assim complexifica sua teoria do objeto, ponderando sobre o desejo inconsciente por meio do objeto inscrito no campo do gozo, logo, uma referência à dupla valência do objeto $a^{7}$. Nota-se, com isso, o movimento pelo qual o "sujeito cria a estrutura do gozo, mas tudo o que podemos esperar disso, até nova ordem, são práticas de recuperação. Isso quer dizer que aquilo que o sujeito recupera nada tem a ver com o gozo, mas com sua perda" (Lacan, 1968-69/2008, p. 113).

Esse seminário ainda apresenta o comentário de Lacan sobre a conferência de Foucault (1994/2009) "O que é um autor?" ". Lembremos que, no final dessa conferência, o grande sociólogo marxista Lucien Goldmann retoma a candente pergunta: "enfim as estruturas descem ou não para a rua?". O peso da crítica de Goldmann consiste no fato de que, para ele, a história não é feita por estruturas, mas por homens engajados na história. No entanto, em sua intervenção, Lacan defendeu que Maio de 1968 demonstrou claramente que as estruturas desceram às ruas, ou melhor, o que ocorreu foi a invasão da rua pelas

7 O objeto a em sua dupla função: a causa do desejo (Lacan, 19621963/2005) e o mais-de-gozar (Lacan, 1968-1969/2008).

8 No dia 22 de fevereiro de 1969, Foucault pronuncia na Sociedade Francesa de Filosofia sua famosa conferência Qu'est-ce qu'un auteur? 
estruturas. Em sua consideração, ficou evidente que não estava interessado na Revolução, e sim na subversão do sujeito pela via do significante, bem como em suas formas de se enredar no laço social.

E, por fim, no Seminário, livro 17: O avesso da psicanálise, Lacan (1969-1970/1992) formaliza sua teoria dos discursos como modos de ordenamento do gozo. Com efeito, desenvolveu quatro discursos como formas de estruturação do laço social (discurso do mestre, da histérica, do analista e do universitário), bem como postulou suas respectivas articulações com a clínica psicanalítica.

Mas qual foi o contexto teórico-clínico que permitiu a Lacan formular sua teoria dos discursos? Como quase tudo em psicanálise, o caminho foi aberto por Freud.

A teoria da identificação que Freud (1921/1988) disseca em "Psicología de las masas y análisis del yo" apresenta que nos juntamos, que nos unimos por algo que temos em comum. Portanto a identificação imaginária no plano do eu ideal (como constituída) é formatada pela identificação simbólica no plano do ideal do eu (como constitutiva) (Žižek, 1990/1992). Em outras palavras, na relação com os outros no laço social, há traços do imaginário que estabelecem uma relação especular, na qual o outro surge duplicado: como rival e como a imagem que é suporte do desejo, ou seja, tanto encobre quanto contém o objeto causa do desejo. Contudo a linguagem (corpo-simbólico) "precede" o sujeito, na medida em que o desejo é determinado pelo simbólico e causado pelo real do objeto $a$. Assim, o que Lacan recupera desse texto freudiano é o conceito de "traço unário" (einziger Zug), para apontar as características peculiares da identificação simbólica.

Se, por um lado, há uma consideração de que o traço unário pode ser estruturalmente arbitrário, por outro, sua função sobre o sujeito não é nada arbitrária, pois a singularidade do traço é uma marca distintiva da coalescência entre o significante e o gozo. Os discursos como aparelhos de linguagem estão em pleno trabalho, assim a renúncia ao gozo produz um efeito de perda e o traço que o marca cria a topologia do gozo: o mais-degozar como efeito do discurso.

Nesse itinerário, Lacan reitera que a entrada do sujeito na linguagem como representado pelo significante demonstra que nessa operação se efetiva uma perda ligada ao conceito de objeto $a$, que o gênio de Freud postulou pela via da repetição. Desse modo, "outra coisa surge no lugar do gozo, ou seja, o traço que o marca. Nada pode se produzir aí sem que um objeto seja perdido." (Lacan, 1968-1969/2008, p. 21)

A teoria dos discursos, portanto, indica que também nos juntamos para evitar algo, para negar algo ou, ainda, para contornar algo que seria impossível.

Nesse sentido, Freud (1925/1988) menciona uma colocação chistosa que dizia que algumas profissões são impossíveis, isto é, o governar e o educar, ao passo que adiciona uma terceira - a saber -, o analisar: o psicanalisar, desse modo, como uma profissão impossível ${ }^{9}$. Lacan, (1969-70/1992), por sua vez, recupera essa construção freudiana e acrescenta uma quarta: o fazer desejar. Dessas quatro tarefas impossíveis deduz quatro discursos como formas de estruturar o laço social. Assim, em torno do Mal-estar ${ }^{[10] 10}$ (Unbehagen) enquanto impossível se estruturam quatro discursos. Os discursos são, portanto, aparelhos de linguagem que ordenam o gozo.

$\mathrm{Na}$ teoria dos discursos o lugar da verdade é um lugar abrigado, a tal ponto que pela verdade se produz o giro discursivo (transformação discursiva). O lugar da verdade, com efeito, suporta o lugar do agente que se relaciona com o outro, extraindo dele uma produção. Nesse sentido, os discursos apresentam uma estrutura quadrípode que funciona em progressão ou regressão em relação aos outros discursos. Sua operacionalidade implica: os lugares (do agente, do trabalho, da verdade e da produção), os elementos (S1, S2, \$, a) e os giros discursivos (a produção dos discursos: do mestre, da universidade, da histeria e do analista).

Com efeito, os discursos são laços sociais que se caracterizam por diferentes formas de se relacionar com esses impossíveis, que mudam de aspecto quando mudamos o laço social. No discurso do mestre está posto o impossível de governar. Já no discurso universitário, o impossível de educar. O discurso histérico traz o impossível de fazer desejar. E por fim, o discurso analítico o impossível de analisar.

Entretanto, no tocante à lógica do consumo, o discurso capitalista surge como uma corruptela do discurso do mestre, sendo, desse modo, essa operação que confere um estilo capitalista para o ordenamento discursivo. Não obstante, existe uma longa discussão sobre a consideração do discurso capitalista como um quinto discurso. Em linhas gerais, neste artigo, utilizaremos uma acepção que reconhece o discurso capitalista como uma expressão do discurso universitário, o que nos permitiu, mais adiante, posicionar o diagnóstico de Lacan sobre a degenerescência do significante-mestre e a estruturação pervertida do laço social no capitalismo (Lacan, 1969-1970/1992).

Com isso, o foco central da investigação de Lacan se desloca para construir uma teorização sobre o sujeito no laço social, tomado por ele como laço discursivo. Esse giro teórico abre a psicanálise como ferramenta para a crítica social e para uma clínica psicanalítica mais esclarecida sobre os modos de enredamento do sujeito na sociedade.

9 Freud (1925/1988) no Prólogo a August Aichhorn, Verwahrloste Jugend, fala da prática psicanalítica pelo curar (Kurieren) como impossível. No entanto, em seu texto de 1937, Análisis terminable e interminable, aborda o impossível de psicanalisar pelo Analysieren. Nas palavras de Freud (1937/1988): "Y hasta pareciera que analizar sería la tercera de aquellas profesiones «imposibles» en que se puede dar anticipadamente por cierta la insuficiencia del resultado. Las otras dos, ya de antiguo consabidas, son el educar y el governar" (p. 249).

10 Certamente, o lendário texto de Freud (1929/1988), "El malestar en la cultura", foi uma fonte de inspiração incontornável para Lacan (19691970/1992) elaborar sua teoria dos discursos. 


\section{A sutileza da crítica de Lacan à degenerescência do significante-mestre: o discurso universitário enquanto mestre pervertido}

No Seminário, livro 17, Lacan (1969-1970/1992)

dedica muitas páginas para analisar o discurso universitário e a subsequente degenerescência $/$ span $>$ do significante-mestre. Nesse momento, há uma crítica bem elaborada às palavras de ordem que são proferidas sob a rubrica do termo revolução. Como vimos anteriormente, sua preocupação enquanto psicanalista estava voltada para a subversão do sujeito pela via do significante. $\mathrm{O}$ sujeito que Lacan evoca nesse seminário é o capitalista (siderado pela mercadoria) e, inclusive, há um corolário com o estudante enquanto $a$ studado - referido como uma unidade de valor, como um objeto astudado.

O fulcro de sua crítica ao discurso universitário consistiu em denunciar a degenerescência do significantemestre, ou seja, Lacan (1969-1970/1992) localizou uma passagem do discurso do mestre (antigo) para o discurso da universidade (mestre moderno). Em seu entendimento, o discurso universitário produziu uma espécie de "tirania do saber" envelopada pela burocracia, culminando em uma forma pervertida de estruturação (o mestre pervertido). O universo da crítica de Lacan ao discurso universitário estava amplamente marcado pela burocracia que envolvia, especificamente, a situação da Universidade na França, a tal ponto que reduzia a experiência do ensino a mera unidade de valor. O estudante havia se tornado um astudado, isto é, um produto do saber tirânico da universidade, tendo em vista que, no discurso universitário, o significante-mestre está escamoteado pelo saber.

Lacan faz um elogio a determinada propriedade do significante-mestre: seu ponto de estofo que garante a função de legibilidade. Ou seja, reconhece que ele comanda o ordenamento social (discursivo) e sustenta uma função coletivizante. Temos, portanto, o Ideal de que há Um que faz andar o mundo, o que sempre exige uma renovação constante, na maioria das vezes representada por uma mudança de mestres na ordem social. Há, assim, no princípio das revoluções, uma grande utopia de que há Um que faz a coisa funcionar (Soler, 2010).

Nessa ponderação, o significante-mestre é o que define a legibilidade, ou seja, um princípio de ordem discursiva que funciona como um aparelho de linguagem, ordenando, desse modo, as relações sociais. Com efeito, configura o princípio de toda interpretação, na medida em que fixa o elemento que possibilita o efeito de leitura, tornando a ordem discursiva interpretável.

Marx, por exemplo, introduziu um significantemestre, o fetichismo da mercadoria, que lhe permitiu "ler" o capitalismo em ascensão na sociedade burguesa do século XIX. Esse significante fez aparecer uma ordem oculta: a expropriação da mais-valia. Freud, por sua vez, identificou outro significante-mestre, o sintoma, que lhe permitiu "ler" a divisão subjetiva e descobrir o inconsciente (Soler, 2010).
Por outro lado, no discurso do mestre pervertido, que é o discurso da universidade (em sua face capitalista), em sua mudança de lugar, o significante-mestre perde tanto sua função de ordenamento quanto seu efeito de legibilidade. O que aconteceu foi a instituição de um tráfico do saber (coroamento das teses) sustentado pelo nome do autor, que avaliza de forma totalitária a legitimidade da ordem discursiva (Soler, 2010).

Com efeito, o significante-mestre se tornou o nome do autor que garante a tirania do saber. O princípio de legibilidade é suspenso, aparecendo em seu lugar uma forma de promoção pessoal, sustentada na hiperindividualização da era moderna. Com isso, o nome do autor atrapalha o ordenamento do laço social, que é reduzindo às sociedades de autores (Soler, 2010). Da mesma forma, promove-se um campo inflacionado de citações, referenciamentos e autorreferenciamentos, assim como se produz um esgotamento do campo da criatividade e da originalidadea singela marca da singularidade.

Assim, a consideração maior de Lacan se refere ao fato de que a revolução consiste em voltar ao ponto de partida, como no caso das revoluções dos planetas, o que é outra maneira de dizer que isso pode levar de volta a outro significante-mestre, já que não existe ordem que não dependa do significante-mestre. Aqui, de certo modo, reside o âmago da crítica de Lacan aos estudantes: "É ao que vocês aspiram como revolucionários, a um mestre. Vocês o terão" (Lacan, 1969-1970/1992, p. 218).

Para Lacan (1969-1970/1992), o movimento "revolucionário" dos universitários estava caindo em uma espécie de efusão, isto é, em uma "perda de potência" (uma impotência). Sua crítica apontava que toda a agitação, toda palavra de ordem demandava uma troca de mestre, o que estava produzindo uma forma de apagamento da causa do desejo. Os estudantes não notavam que as palavras de ordem funcionavam como uma forma de se manterem presos ao discurso do mestre moderno, representado pelo discurso universitário (Laia, 2009).

Diante desse cenário, o que poderia colocar um limite para os efeitos do discurso do mestre pervertido seria a vergonha de viver. Esse apontamento se refere ao fato de que o discurso analítico faz emergir o significantemestre como uma produção singular do sujeito, assim como produz efeitos que posicionam as coisas do amor no laço social. Se o gozo em si não faz laço, a intersecção entre o amor e o desejo é uma das formas privilegiadas de enlaçamento social.

\section{A virtude da coragem e o afeto da vergonha}

Diante de tais delineamentos, constatamos que o posicionamento crítico de Lacan apresenta um duplo encaminhamento: por um lado, há uma crítica ao lugar que ocupam a universidade e o campo do saber tirânico, portanto, sintônicos aos acontecimentos de Maio de 1968; por outro, uma crítica que localizava nas palavras de ordem proferidas como latidos uma aspiração a um novo mestre, 
que, de certa forma, quando observada em seus efeitos $a$ posteriori, nota-se que representou uma contraposição à própria noção de ato enquanto um acontecimento.

Todavia, quando o acontecimento Maio de 1968 é visualizado de modo abrangente em toda sua complexidade, perguntamos: o que teria sido a história das políticas de emancipação e dos movimentos revolucionários sem esse acontecimento? Se houve excessos e retrocessos, a reflexão, contudo, encaminha-se para além da aspiração ao mestre, considerando-se tanto a dimensão do acontecimento insabido, que aqui articulamos como Real, quanto à subversão do saber do mestre (pervertido) e seus cálculos cínicos. Com isso, pretende-se ensaiar, a posteriori, sua causação e repercussões no laço social e no tipo de política que se produziu.

Retomando o filosofo francês Alain Badiou (2009/2012), é possível situar determinadas respostas de âmbito geral, que representam uma espécie de escólio ao acontecimento Maio de 1968.

Por um lado, uma resposta que pode ser considerada pessimista, tendo em vista que o líder da revolução estudantil Daniel Cohn-Bendit, que representava um símbolo para o Maio de 1968, entende que sua potência revolucionária está morta. Outra resposta pessimista afirmou que o verdadeiro vencedor de Maio 1968 é o próprio capitalismo neoliberal desenfreado, que envolveu o mundo com ideias libertárias que, na verdade, estavam envelopadas pelo individualismo e pelo universo do consumismo. Por outro lado, desponta uma reposta otimista, que posiciona Maio de 1968 como um movimento que recobrou a coragem para reagir, produzindo uma ideia que nos diz que uma nova configuração política é possível, tendo em vista que o capitalismo não é necessário.

Nessa perspectiva, o saldo que obtemos desse balanço crítico consistiu na reflexão sobre a produção e o engendramento, nos dias de hoje, dos tipos de organização do saber-poder: seja a manutenção do mestre, seja sua substituição ou mesmo a possibilidade do avesso de sua posição. O que está indicado nesse expediente é a possibilidade de reinvenção do laço social por sucessivas subversões e "revoluções". Aqui está posicionada toda a história das políticas de emancipação e dos movimentos sociais.
Certamente, um caminho possível foi proposto por Lacan, em sua consideração sobre o lugar da vergonha na produção do giro discursivo. Dirá Lacan (1969-1970/1992): "morrer de vergonha é um efeito raramente obtido" (p. 191). A vergonha, embora em uma época que não cessa de depreciá-la, pode dar suporte para promover a mudança de um laço social degradado. Dito de outro modo, nomear a vergonha pelo discurso analítico, seja dos seus excessos, seja dos excessos dos laços sociais de nosso tempo, pode conferir dignidade ao significante, pois evoca a dimensão da singularidade. Lacan (1969-1970/1992), dessa forma, posiciona que a vergonha é o buraco de onde brota o significante-mestre. A vergonha, com efeito, é designada pelo que singulariza um sujeito no campo do Outro. Ter vergonha, portanto, é uma espécie de marca da dignidade humana e da potência do laço social, na medida em que representa um recurso contingencial essencial para a produção do giro discursivo (Laia, 2009). Assim, a vergonha dos excessos produzidos no laço social de nosso tempo tem a potência de produzir um corte no campo do gozo e do discurso cínico, retraçando uma direção ética no laço social.

Desse modo, para além do lamento do suposto fracasso ou da fruição dos avanços, a atualidade dessa reflexão será pensar sobre o que nos causam hoje, como cidadãos, mas também como professores, os acontecimentos de nossa época. Com isso, podemos ficar entre a rua e a sala de aula, reeditando o dilema de Lacan. No entanto, podemos ser convocados a estar à altura do acontecimento que Maio de 1968 representou. Nesse contexto, somos inspirados na "coragem de ter uma ideia" (Badiou, 2009/2012, p. 41), o que pode implicar um reposicionamento do discurso capitalista - discurso que mimetiza as condições da perversão no laço social. Isso nos convoca, enquanto psicanalistas, a sustentar tanto um posicionamento ético (do desejo e do bem-dizer) quanto uma posição de coragem perante os acontecimentos de hoje. E acolher algo dessa ordem é o desafio para qualquer crítica que não queira estar submetida à bandeira do reducionismo e da adaptação e que entende que resgatar o sujeito em sua singularidade não representa meras palavras vazias, mas, antes, produtoras de ato e acontecimento, podendo, sim descer às ruas.

\section{Event and act: reflections of psychoanalysis on the repercussions of May 1968}

Abstract: Our article results from the concern of psychoanalysts about the success or failure of social movements as a response to the current institutional, political and social crisis. We emphasize the epistemological and political dilemma present in the question that went through the May 1968 movement: after all, do structures reflect on the streets or not? To answer this question, we examined the effects of the movement a posteriori and compared them with Lacan's theoretical work. Based on this critical balance, we consider May 68 as a reminder that structuring a new form of politics is possible. Naming the shame of excesses in the social ties of our time may confer dignity to the signifier and produce a sufficient point by the dimension of ethics and uniqueness. Such a position produces a discursive twist, incited by the courage to have an idea and the possibility of reinventing the social bond by successive subversions and revolutions.

Keywords: event, social bond, shame, politics, psychoanalysis. 


\section{Événement et acte : réflexions de la psychanalyse sur les répercussions de mai 1968}

Résumé : L'article découle de la préocupation des psychanalystes face au succès ou à l'échec des mouvements sociaux en réponse à la crise institutionnelle, politique et sociale actuelle. Nous soulignons le dilemme épistémologique et politique dans la question qui a traversé le mouvement de mai 1968: enfin, les structures descendent ou non dans la rue? La voie adoptée consiste à examiner les effets du mouvement a posteriori et à les comparer avec les conceptions théoriques de Lacan. Le résultat que nous obtenons de ce bilan critique a été de considérer mai 1968 comme un événement qui nous rappelle qu'il est possible de structurer une nouvelle politique. Nommer la honte des excès dans les liens sociaux de notre temps peut donner de la dignité au signifiant et produire un point de suffisance pour la dimension de l'éthique et de singularité. Une telle position produit un tournant discursif, encouragé par le courage d'avoir une idée et la possibilité de réinventer le lien social par des subversions et des révolutions successives.

Mots-clés : événement, lien social, honte, politique, psychanalyse.

\section{Acontecimiento y acto: reflexiones del psicoanálisis sobre las repercusiones de Mayo del 1968}

Resumen: El artículo surge de la inquietud de psicoanalistas frente al éxito o fracaso de los movimientos sociales como una respuesta a la actual crisis institucional, política y social. Se destaca el dilema epistemológico y político presente en la indagación que recorrió el movimiento de Mayo del 68: ¿las estructuras descienden o no a la calle? Para ello, se examinan los efectos del movimiento bajo la luz de las concepciones teóricas de Lacan. De ese balance crítico se considera el Mayo del 68 como un acontecimiento que recuerda que es posible estructurar una nueva forma de política. Al nombrar la vergüenza de los excesos en los lazos sociales de nuestro tiempo se puede conferir dignidad al significante y producir un basta por medio de la dimensión de la ética y de la singularidad. Esto produce un giro discursivo, incitado por el coraje de tener una idea y la posibilidad de reinventar el lazo social por sucesivas subversiones y revoluciones.

Palabras clave: acontecimiento, lazo social, vergüenza, política, psicoanálisis.

\section{Referências}

Agamben, G. (2002). Homo Sacer: O poder soberano e a vida nua I (H. Burigo, trad.). Belo Horizonte, MG: Editora UFMG. (Obra original publicada em 1995)

Agamben, G. (2011). O reino e a glória: Uma genealogia teológica da economia e do governo (S. J. Assmann, trad.). São Paulo, SP: Boitempo. (Obra original publicada em 2007)

Althusser, L. (1985). Freud e Lacan: Marx e Freud (W. J. Evangelista, trad., 2a ed.). Rio de Janeiro, RJ: Graal. (Obra original publicada em 1964)

Badiou, A. (1994). Para uma nova teoria do sujeito: Conferências brasileiras (E. X. da Silva, \& G. Sodré, trads.). Rio de Janeiro, RJ: Relume-Dumará.

Badiou, A. (2012). A hipótese comunista (M. Echalar, trad.). Coleção Estado de Sítio. São Paulo, SP: Boitempo. (Obra original publicada em 2009)

Deleuze, G. (1998). Lógica do sentido (L. R. S. Fortes, trad.). São Paulo, SP: Perspectiva. (Obra original publicada em 1969)

Evangelista, W. (1985). Prefácio. In L. Althusser, Freud e Lacan: Marx e Freud (W. J. Evangelista, trad., 2a ed., pp. 7-43). Rio de Janeiro, RJ: Graal. (Obra original publicada em 1964)

Foucault, M. (2009). O que é um autor? In M. B. da Mota (Org.), Estética: Literatura e pintura, música e cinema (I. A. D. Barbosa, trad., pp. 264-298). Coleção Ditos \& Escritos III. Rio de Janeiro, RJ: Forense Universitária. (Obra original publicada em 1994)
Freud, S. (1988). Psicología de las masas y análisis del yo. In Obras completas (J. L. Etcheverry, trad.,vol. 18, pp. 63-136). Buenos Aires: Amorrortu Editores. (Obra original publicada em 1921)

Freud, S. (1988). Prólogo a August Aichhorn, Verwahrloste Jugend'. In Obras completas (J. L. Etcheverry, trad., vol. 19, pp. 296-298.). Buenos Aires: Amorrortu Editores. (Obra original publicada em 1925)

Freud, S. (1988). El malestar en la cultura. In Obras completas (José L. Etcheverry, trad., vol. 21, pp. 57-140). Buenos Aires: Amorrortu Editores. (Obra original publicada em 1929)

Freud, S. (1988). Análisis terminable e interminable. In Obras completas (José L. Etcheverry, trad., vol. 23, pp. 211-254). Buenos Aires: Amorrortu Editores. (Obra original publicada em 1937)

Lacan, J. (1967). O seminário, livro 15: O ato psicanalítico, 1967. Seminário inédito. Recuperado de http://bit.ly/ 3 qodN3Q

Lacan, J. (1992). O seminário, livro 17: O avesso da psicanálise, 1969-1970 (A. Roitman, trad.). Rio de Janeiro, RJ: Zahar.

Lacan, J. (1998). Função e campo da fala e da linguagem em psicanálise. In Escritos (V. Ribeiro, trad., pp. 238-324). Rio de Janeiro, RJ: Zahar. (Obra original publicada em 1953) 
Lacan, J. (1998). Subversão do sujeito e dialética do desejo no inconsciente freudiano. In Escritos (V. Ribeiro, trad., pp. 807-842). Rio de Janeiro: Zahar. (Obra original publicada em 1960)

Lacan, J. (2005). O seminário, livro 10: A angústia, 1962-1963 (V. Ribeiro, trad.). Rio de Janeiro, RJ: Zahar.

Lacan, J. (2008). O seminário, livro 11: Os quatro conceitos fundamentais da psicanálise, 1964 (M. D. Magno, trad.). Rio de Janeiro, RJ: Zahar.

Lacan, J. (2008). O seminário, livro 16: De um Outro ao outro, 1968-1969 (V. Ribeiro, trad.). Rio de Janeiro, RJ: Zahar.

Laia, S. (2009). Análise e interpretação de uma efusão coletiva: os discursos, a ação lacaniana a partir de maio de 68 e suas consequências. Almanaque online. Recuperado de https://bit.ly/3idAc12

Lévi-Strauss, C. (2008). Antropologia estrutural (B. PerroneMoisés, Trad.). São Paulo, SP: Cosac Naify. (Trabalho original publicado em 1974)

Motta, A. (2012). As estruturas não descem às ruas: Lévi-Strauss, mai soixante-huit e o fim do estruturalismo. Politica \& Trabalho: Revista de Ciências Sociais, (36), 257-266. Recuperado de http://bit.ly/3qj1KEZ
Quinet, A. (2009). As 4+1 condições de análise. Rio de Janeiro, RJ: Zahar. (Obra original publicada em 1991)

Rosa, M. D. (2004). A pesquisa psicanalítica dos fenômenos sociais e políticos: Metodologia e fundamentação teórica. Revista Mal-Estar e Subjetividade, 2(2), 329-348.

Rosa, M. D., Penha, D. A., \& Alencar, R. (2017). A gestão social na lógica da guerra e o poder soberano: Ética e política no nosso tempo. Revista da Associação Psicanalítica de Porto Alegre, (51-52), 65-79.

Shepherdson, C. (2007). Uma libra de carne: a leitura lacaniana d'O visível e o invisível (R. Manzi Filho, trad.). Discurso: Revista do Departamento de Filosofia da USP, 36, 92-124.

Soler, C. (2010). O estatuto do significante mestre no campo lacaniano. A Peste: Revista de Psicanálise e Sociedade, 2(1), 255-270.

Žižek, S. (1992). Eles não sabem o que fazem: O sublime objeto da ideologia (V. Ribeiro, trad.). Rio de Janeiro, RJ: Zahar. (Obra original publicada em 1990)

Recebido: 09/09/2018

Revisado: 02/08/2020

Aprovado: 13/12/2020 